Article

\title{
Implementing Social Sustainability for Innovative Industrial Work Environments
}

\author{
Agneta Sundström $\mathbb{D}^{\text {, Zahra Ahmadi * }}{ }^{\mathbb{D}}$ and Kristina Mickelsson \\ Department of Business \& Economic Studies, University of Gävle, 80176 Gävle, Sweden; awd@hig.se (A.S.); \\ kristina.mickelsson@hig.se (K.M.) \\ * Correspondence: zaaahi@hig.se
}

Received: 14 May 2019; Accepted: 18 June 2019; Published: 20 June 2019

\begin{abstract}
Industrial companies are in a situation that requires them to reconsider their social sustainability agenda in order to attract new employees. Building upon interviews with CEOs and HR managers in 20 small medium enterprises (SMEs), this study aims to analyze how high-tech companies and industrial engineering companies define and implement social sustainability into business strategies and operations. Data was collected from 20 interviews and secondary information coded for categorical data analysis in SPSS Statistics 22 software. The findings show that although the companies have adopted several kinds of International Organization for Standardization (ISO) standards, social sustainability is still absent from their operational activities and is considered of lower importance than environmental sustainability. Thus, the implementation of social sustainability can be considered symbolic rather substantive. The study also shows differences between the two groups of companies. The high-tech company group pays little attention to social sustainability aspects, instead focusing on product innovation development. While the industrial engineering group has some interest in social sustainability, their focus is primarily on issues linked to health and safety in order to meet increasing demands from supply chain compliance. Neglecting social aspects of sustainability, such as addressing gender equality and diversity, may cause difficulties in attracting a new workforce.
\end{abstract}

Keywords: social sustainability; high-tech companies; industrial engineering companies; preparation; environmental sustainability

\section{Introduction}

Industrial companies are in a situation that requires them to reconsider their social sustainability agenda in order to attract a new workforce [1]. This applies specifically to male-dominated industries in rural areas, where the integration of social aspects of sustainability has traditionally been underestimated as an important part of the business. These industrial areas are experiencing population decline, demographic changes, and normative male values that affect working conditions and challenge the conditions for developing innovative working environments [2,3]. Thus, in response to these challenges, a sustainable working environment design is needed that takes into account human aspects but also focuses on economic improvement [4]. Trends like the increased proportion of women in higher education, the increased proportion of well-educated immigrants, increased demands from customers, suppliers, and financiers, and problems with maintaining interest among skilled people in industrial work are pressing companies to increasingly implement social sustainability aspects in business operations [1].

Most executives worldwide believe in sustainability for financial success, but few have succeeded in strategically implementing the social dimension as an integrated part of business operations $[5,6]$. Many large companies have accepted and are practicing economic and environmental aspects of 
sustainability but show limited interest in defining and implementing social concerns in business operations $[2,3,5,7,8]$.

However, in recent years, researchers have shown growing interest in studying the social dimension of corporate social responsibility (CSR) as a corporate duty and a part of business integral to human resources (HR) $[9,10]$. Ravazzani investigated the implementation of diversity management by looking at managerial interventions and contextual factors that influence business activities [10]. This research shows that companies in Italy work with social factors as an isomorphic expectation to gain legitimacy in society for their business. Many of the companies work with diversity management to meet environmental expectations of compliance and are oriented toward opportunities. Colgan evaluated how U.K. companies act to develop diversity management in environmental work, claiming that diversity management approaches need to be understood in a global context, including a consideration of the country of origin and the historical path of diversity initiatives [9]. Furthermore, a study of Italian banks shows that customers' gender, age, and education can have an impact on how they relate to an organization's social sustainability work [11]. Attention is also paid to health and safety [3] as part of company risk management [12] or its influence on workforce behavior [13].

This study aims to explore how industrial companies in rural areas define and implement social sustainability as an integrated concept in their business agenda to improve work environment innovativeness. Twenty small and medium-sized enterprises (SMEs) participated in the study. Understanding how SMEs perceive and practice social sustainability is essential, since according to Statistics Sweden 99\% of the corporations in Sweden have less than 250 employees [14]. The chosen SMEs represent industrial companies within both the high-tech and engineering industries. SMEs in rural areas in Sweden are often in networks together with international corporations in global supply chains. Therefore, even large enterprises have a need to understand how SMEs perceive and implement social sustainability aspects into their business activities.

\section{Literature Review}

The 2015 UN agreement on 17 global goals for sustainable development highlighted sustainability issues that are not strictly economic, instead including environmental and social issues concerning globalization, empowerment, and equality. In recent years, it has become increasingly important to consider human aspects in all business activities and strategies. Therefore, the UN global goals for sustainable development clearly focus on social sustainability, addressing gender equality, and diversity [15]. According to the European Commission [16] arguments for sustainable development, the quality of human resources is a key competitive issue, requiring constant management attention to several dimensions of economic, social, and environmental changes. This is especially important in times of industrial downsizing, where the companies must simultaneously have personal resources for coping and be thriving in order to meet strategic challenges for building sustainable work environments [17]. In facing new obstacles related to the increased movement of labor and expected future demographic changes in society, it has become increasingly important for corporate managers to pay careful attention to how to recruit and retain employees. Apart from the economic benefits of labor competence attributes, a reassessment of labor initiates critical social processes, simultaneously requiring changes in labor attitudes and image-shaping activities to attract new labor [18]. Ma and Kremer discuss social sustainability and argue that an organization's working time is important for job creation, which has an impact on the workforce and the social quality of society [4].

Serious attempts to implement social sustainability send signals of honesty, reliability, and image, influencing the organization's ability to recruit and retain high-quality employees [19]. Public expectations that businesses will act as citizens and work for the maintenance of the common good have put pressure on management to shape business ethics into a formalized structure [20], so that ethics become integrated into business differentiation strategies [19,21]. How management affects workforce changes and takes social sustainability issues seriously is of crucial importance for business competitiveness, survival, and local community development. 
A company's orientation toward social sustainability is closely connected to its ability to develop innovativeness, representing an organization's entrepreneurial and cultural orientation [22]. From a market-orientation perspective, innovativeness represents the process of attaining innovation in terms of openness to new ideas and developing the learning capacity to implement creative viewpoints in the organization as culture [23]. Implementing social sustainability seriously by improving internal learning capacity could be seen as the means to reach innovation as the end stage [24,25], since it helps speed up the process of reaching competitive advantages [26]. How firms develop the capacity to create new ideas as a culture of innovative thinking is, thus, crucial for developing business and being sensitive to market demands [24].

Vallance et al. discuss three social dimensions that enhance the understanding of how to define social sustainability [27]. They considered social homogeneity, access to goods and services, and employment as the most significant preconditions to understanding social norms and values as part of the culture. Lin et al. [28] argue also that social sustainability issues are influenced by democracy and governance conditions, social cohesion, and the ability to have a high quality of life. These kinds of social aspects are most significant in research into global conditions that focuses on the study of poor social conditions in emerging economies $[7,27]$. This growing interest depends, according to Mani et al. [29], on the increased stakeholder pressure on purchasers to address their responsibilities when developing global supply chain relationships. The pressure to sustain responsibility requires corporate leaders to develop a deep understanding of the social parameters relevant for these countries [27,29]. Companies in more developed countries commonly pay attention to the lack of basic amenities, the use of child labor, poor living conditions, and poverty in emerging economies [29,30]. Other issues relate to intra- and intergenerational equality and the distribution of power, employment, resources, education, provision of basic infrastructure and services, justice, and access to influential decision-making fora and the need for capacity building $[27,30,31]$. In short, social requirements on supplier compliance are apparent when doing business in developing countries, whereas social parameters integration in developed countries' businesses is less evident.

Even in developed countries, practices of sustainability do not indicate that serious problems around poverty, malnutrition, poor health, and inadequate housing are resolved [27,32]. This can be noticed, for instance, in dealing with the increased awareness of social sustainability in areas like urban planning [27,33] and new forms of work organization [34]. A main problem is that social sustainability is often linked to HR activities [35] without being strategically integrated as part of business core activities and practices, as environmental and economic concerns are [2]. Studies show, for example, that women have fewer opportunities for career chances in typically male-dominated work environments, which calls for developing flexible work arrangements [35]. Longoni et al. argue that human resource management and organizational practices call for newer forms of work organization and learning, in which sustainability strategies are integrated throughout the company [34].

\subsection{Social Sustainability Definition and Operationalization}

Although several authors have attempted to develop theoretical schemes to define and study the social sustainability concept, two main barriers have slowed down the development of the social dimension in both research and practice [33]. The first barrier concerns how social sustainability can be defined, framed as the substantive dimension (what it is), whereas the second barrier concerns how the concept can be operationalized and implemented, representing the procedural dimension (how it is practiced) in business operations [33] (p. 11). Boström discusses social sustainability both as a strength for its flexibility and as a weakness, since an explanation is always needed to clarify its meaning [33]. This indicates that organizations not only need to know what social sustainability is but also need to have the capacity to translate the subjective "what" to "how", by engaging in innovative capacity-building processes before efforts lead to socially sustainable integration.

Similarly, Galuppo et al. [36] discuss two dimensions of sustainability, where the first refers to the content of the concept addressing "what is" social sustainability and the second "which" dimensions 
could be considered "within its boundaries." The "which" dimension deals with the process of how organizations achieve their goals. In terms of defining the social "what" dimension of sustainability, one suggested definition is to identify "the impact of products or operations on human rights, labor, health, safety, regional development, and other community concerns" [36] (pp. 687-689).

Related to the boundaries of sustainability and which dimensions to practice, a company's vision, mission, and values can act as "guideposts to sustainability" to identify and set the frames of action [6]. The vision announces "what future we seek to create"; the mission relates to achievements of goals and provides information of "why we exist" and values related to "how to achieve the vision." This means that how companies strategically and innovatively act based on their vision plays a significant role in understanding how to achieve the main goals of social sustainability and the impact of this strategy on employees' values. Moreover, Galuppo et al. argue that incorporating social sustainability into the company vision and values represents an idealistic orientation aimed at creating shared values that, in the long run, balance both economic and social needs [36]. These companies are few but open to changing traditional structures and the culture.

Katsoulakos and Katsoulakos emphasized how social sustainability needs to be linked to strategic responsiveness to fulfill social requirements through developing dynamic capabilities in the organization [2]. It is not enough to align social sustainability to shared values; the company must also respond and act based on these values. Galuppo et al. argue that companies need to engage and act seriously, not only in response to shareholder demands or the law [36].

Blake-Beard et al. [35] focused on how companies can maximize their human capital by increasing the workforce ability in situations of increased complexity at work. By adopting a behavior perspective, Kira and van Eijnatten see social sustainability as "an ability to find ways to deal with challenges and capability to create new opportunities for a productive existence" [37] (p. 744). They especially emphasize the ability to manage the dynamic state of sustainability, arguing that organizations have to take into account both structural and cultural capabilities for creating a sustainable work organization. A sustainable functioning system is more effective under external pressures [37].

Dempsey et al. [38] argue that social sustainability should be seen neither in terms of absolute conditions nor as a constant but as a dynamic, innovative concept that changes over time. Vallance et al. discuss three different types of social sustainability that influence how the concept is practiced over time: (1) developing sustainability regarding basic needs for building social capital; (2) bridging sustainability related to changing behavior, with a focus on transformative approaches; and (3) maintenance sustainability, which relates to "practices, preferences, and places people want to see maintained (sustained)" [27] (p. 344). According to the authors, these three types overlap and, in certain situations, align.

\subsection{Formal Support for Social Sustainability}

Because social sustainability has been difficult to define, several standards and guidelines have been developed to support its implementation. Attention is often drawn to the dimensions that go under the Global Compact umbrella of ten principles and issues of leadership related to human rights and labor [39]. The first human rights principle states that businesses should support and respect the protection of internationally proclaimed human rights, while the second principle seeks to make sure that it does not abuse human rights. Labor principles 3-6 deal with freedom of association and the effective recognition of the right to collective bargaining, the elimination of all forms of forced and compulsory labor, the effective abolition of child labor, and efforts to eliminate discrimination in employment and occupation. In developing countries, principles 3-4 are of the highest priority, while in developed countries principle 6 is the most relevant (e.g., diversity, equality, health and safety). While the Brundtland Report titled Our Common Future (1987) contributed to significant improvements within the sustainability field [27] (p. 343), the UN Global Compact principles have provided policy tools used by businesses as guidance to develop codes of conduct. Based on the 
connection to human aspects, social sustainability is defined as the human code of conduct requiring that social issues need to be achieved in an equitable, inclusive, and prudent manner [29].

Several International Organization for Standardization ISO standards have been developed to guide the implementation of sustainability in corporate organizations. Common standards are ISO 9001 (Quality Management), ISO 14001 (Environmental Management), and OHSAS 18001 (Occupational Health and Safety Management, which will be replaced by ISO/DIS 45001). Since certification in any of these standards requires a review of activities, procedures, and the training of employees, these signal commitment to sustainability in organizations but not how they actually practice it. Standards for equality and diversity are still missing but get support from company policies, International Labour Organization (ILO) recommendations, or gender equality acts.

\section{Research Method}

This research explored how 20SMEs in traditionally male-dominated industrial work environments define and work with CSR, with a focus on social sustainability. Given the different business contexts concerning size and industrial context, this research applied a mixed-method approach [40]. The use of both qualitative and quantitative data offers a more comprehensive way to study complex situations [41] and can provide a more complete overview based on different methods and perspectives, which can be called the third research paradigm in research $[42,43]$. Above all, the benefit of the mixed-method approach is that it compensates for faults and limitations of single methods [40,41]. Mixed-method research is considered a successful approach, since research contributes to developing the concepts and applying them [42]. Therefore, the goal of mixed-method research in this study was not to replace either the qualitative or the quantitative approach but rather to draw conclusions from the strengths of both and minimize the weaknesses of single research studies $[42,44]$. The ability to triangulate results from different methods $[40,41]$ creates "opportunities for cross-validation and cross-fertilizing procedures, findings, and theory" [40] (p. 1). The combination of data collection methods allowed us to address a broader set of questions, improving the likelihood of identifying paradoxes and seeing unexpected outcomes, as suggested by Gil-Garcia and Pardo [41]. In this study, these possibilities constituted important criteria for the choice of method, because we investigated the preconditions and the preparation for involved companies to transform toward social sustainability.

\subsection{Research Design}

This paper adopted an exploratory research design [45]. The companies were selected with the support of innovation centers on the basis that they are representative of regional companies in each sector. The companies were representative of regional high-tech growth and important suppliers to traditional large companies. The mixed method applied combined semi-structured interviews, secondary formal sources (standards and policies), and statistical data from surveys. Structured interviews with the company managers were conducted to gain an up-to-date understanding of their awareness of the sustainability concept, how they work, and how they plan to respond to socially related stakeholder requirements in the future.

Thirteen managers (HR and CEOs) in high-tech companies in central Sweden were interviewed. The regional area is characterized by traditional resource-based industry culture, which in recent years has evolved to comprise high-tech companies governed by technically oriented business logic. It is therefore interesting to study how traditional versus high-tech companies relate to the newer demands for social sustainability. The companies differed according to turnover, size, and industrial context but shared similarities in being technologically driven and requiring a highly educated workforce to stay competitive in national and international markets.

The interviewed managers had a good overview of social sustainability integration, because they were responsible for HR and CEO questions in the companies. According to what we learned in previous meetings, they were finding social integration to be a great challenge to manage. Additionally, these respondents were suitable for this study from theoretical and practical perspectives, because they 
were aware of all activity in the companies [6]. The HR managers were educated in social sustainability issues but had found it difficult to publicize this knowledge within the companies.

They contributed to information about how to approach social sustainability regarding the building of basic needs for human capital, as is also recommended by Vallance et al. [27]. An additional seven interviews were conducted with business managers (CEOs and regional managers) in industrial engineering companies located in central Sweden. Their businesses are strongly influenced by the historical business culture in the region. These were chosen based on (1) being part of a corporate supply chain with long experience in working with sustainability issues, and (2) allowing contrast with the findings of the "newer" high-tech companies to reveal differences between how these two groups of companies are prepared to work with social sustainability requirements. Most of the companies were suppliers and part of a corporate group, but the questions addressed how they work at the local level. Besides offering comparability, the method also gave a picture of how high-tech companies and engineering firms together ensure social sustainability in business.

The interviews were conducted at the companies and lasted 1-1.5 h. An interview guide was developed, with questions and follow-up questions as support. The data were transcribed immediately after the interviews and coded with categorical variables for analysis. Secondary data from company web pages was used to cross-check and complement primary data concerning the size of the workforce, employee turnover, work with social sustainability issues/CSR, standards, and work environment policies. We reviewed the companies' websites to measure how many standards they use as support for social and environmental sustainability, then coded all standards from 1 to 5 , where 1 represents few standards and 5 includes all standards.

\subsection{Coding and Analysis of Categorical Variables}

As the respondents' companies differed in nature and were difficult to compare, the qualitative data were analyzed as text and then coded in SPSS 22 Statistics software as categorical variables for statistical analysis. Converting qualitative data into codes for categorical data analysis enabled us to calculate differences in how the companies and organizations managed variables like degree of CSR implementation, environmental engagement, diversity, equality, policy and standard support, and perceptions of future development of social sustainability. Powers and Xie define categorical variables as "those that can be measured using only a limited number of values or categories" [46] (p. 2). According to them, qualitative variables are categorical and provide possibilities to be ranked (ordinal data) or be used as nominal variables (status without the possibility to be mutually ranked). All interviews were coded and categorized as sustainability dimensions: equality, diversity, health and safety. These represent the core categories of the study and show how the collected data relate to each type of company studied.

In this study, social sustainability was coded based on how the companies work with equality, diversity, and health and safety as social parameters. The degree of equality was coded on a Likert scale of 1 to 5 to analyze the degree of male domination of the workforce (a low to high percentage of male employees). The degree of diversity was coded on a scale of 1 to 5 from a very low degree and homogeneous employment structure to a very highly heterogeneous employment structure. The degree of health and safety was coded as 1 to 5 from very low commitment by the company to very high commitment. To analyze and compare different degrees of how the companies work with sustainability issues, the degree of environmental variables was also coded using the same Likert scale. The coding of environmental sustainability was done to analyze and compare the strength of social responsibility. The interviews were conducted by meeting face to face, using a structured questionnaire to collect data. Encoding the data from 1 to 5 showed how they work with social responsibility issues. A code of 1 represents doing a little work, whereas 5 represents doing all standards in the companies.

To increase the reliability of the codes, secondary data was collected to show if the companies have equality and diversity plans or not (1-0). To cross-check and compare how social and environmental concerns are implemented in the organization, secondary data was collected to analyze the companies' 
work with ISO 9001, ISO 14001, and OHSAS 18001 standards and whether they have equality/diversity policies or not. Comparing the interview data with formal data allowed us to analyze the difference between what the respondents say and what they do, as well as showing how they work based on formal standards and policies. Finally, to examine the need for future development, the standards and policies were summarized and calculated to identify the present conditions of sustainability integration in the two groups analyzed. The scale of $0-5$ ranged from no (0) to very low ( $1=$ having one standard/policy) to very high ( $5=$ having five standards/policies), showing the degree of formalized sustainability.

Figure 1 shows an overview of the process, including the coding and analysis of primary and secondary collected data on sustainability.

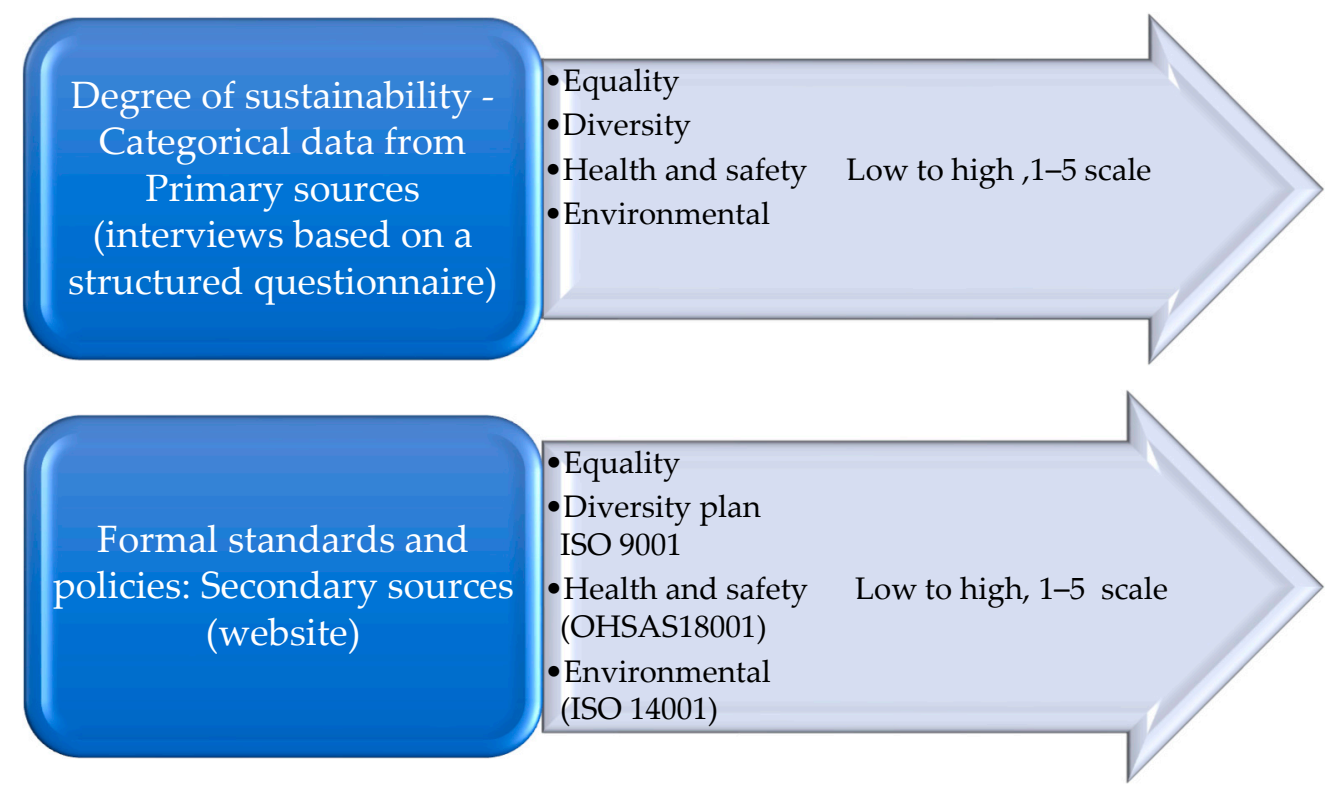

Figure 1. Data collection and analysis.

\subsection{Limitations of the Method}

The use of the mixed-method approach could be criticized as a limitation, because this approach requires careful attention to how data from different methods are coded and combined. These challenges were met by collecting data via a structured interview guide, which was then coded based on the respondents' perception of how much they work on and value various dimensions of sustainability. To give a richer picture of how companies deal with social sustainability and increase reliability of the coding of statistical data, the analysis was supplemented with qualitative data from interviews. Furthermore, as the number of companies was relatively small, there were no missing values in the calculations. The study demonstrates differences based on a small sample set, and further research is needed to see if this difference is more widespread.

\section{Findings}

The measurements show the strengths between what companies say (the formal standards) and what they do (as we received through interviews). We have put them (their actions and the formal policies) in relation to how they formally do what appears in standards found on websites and annual reports. Data based on the distribution of men and women employed in the companies show that in general both industrial groups are male-dominated in employment. Two of the high-tech companies have equal numbers of men and women employed (IDs 2 and 8 in Table 1), while one engineering company has equal men and women employed (ID 17). Table 1 shows the company identification number, number of employees, and the distribution of men and women as the percentage employed in the companies. 
Table 1. Men and women employed in the studied high-tech and industrial engineering companies.

\begin{tabular}{cccc}
\hline ID & Employees & Men $\%$ & Women $\%$ \\
\hline \multicolumn{4}{c}{ High-Tech Companies } \\
\hline 1 & 29 & 83 & 17 \\
3 & 115 & 58 & 42 \\
4 & 800 & 75 & 25 \\
5 & 10 & 72 & 28 \\
6 & 93 & 80 & 20 \\
7 & 88 & 86 & 14 \\
8 & 63 & 87 & 13 \\
9 & 95 & 53 & 47 \\
10 & 122 & 81 & 19 \\
11 & 35 & 74 & 26 \\
12 & 17 & 88 & 12 \\
13 & 15 & 87 & 13 \\
& 20 & 50 & 50 \\
\hline \multicolumn{4}{c}{ Industrial Engineering Companies } \\
14 & 25 & 76 & 24 \\
15 & 1043 & 84 & 16 \\
17 & 152 & 95 & 5 \\
18 & 450 & 53 & 47 \\
19 & 40 & 95 & 5 \\
20 & 9 & 87 & 13 \\
\hline
\end{tabular}

\subsection{Degree of Social and Environmental Engagement}

Table 2 shows the degree to which the companies in the two studied groups worked with environmental and social components of sustainability.

Table 2. Environmental and social sustainability degrees as measured by Likert scale (1-5).

\begin{tabular}{|c|c|c|c|c|c|c|}
\hline \multicolumn{7}{|c|}{ High-tech and Industrial Engineering Companies-Descriptive Statistics } \\
\hline & $\mathrm{N}$ & Minimum & Maximum & Mean & Std. Deviation & Variance \\
\hline Environment degree & 20 & 1 & 5 & 3.20 & 1.361 & 1.853 \\
\hline Equality degree & 20 & 1 & 3 & 1.60 & 0.821 & 0.674 \\
\hline Diversity degree & 20 & 1 & 5 & 1.80 & 1.240 & 1.537 \\
\hline Health and safety degree & 20 & 1 & 5 & 2.55 & 1.468 & 2.155 \\
\hline Social sustainability integration & 20 & 1 & 4 & 1.98 & 0.763 & 0.583 \\
\hline \multicolumn{7}{|c|}{ High-Tech Companies-Descriptive Statistics } \\
\hline & $\mathrm{N}$ & Minimum & Maximum & Mean & Std. Deviation & Variance \\
\hline Environment degree & 13 & 1 & 5 & 2.77 & 1.423 & 2.026 \\
\hline Equality degree & 13 & 1 & 3 & 1.69 & 0.855 & 0.731 \\
\hline Diversity degree & 13 & 1 & 5 & 1.85 & 1.463 & 2.141 \\
\hline Health and safety degree & 13 & 1 & 4 & 2.00 & 1.225 & 1.500 \\
\hline Social sustainability integration & 13 & 1 & 4 & 1.85 & 0.786 & 0.618 \\
\hline \multicolumn{7}{|c|}{ Industrial Engineering Companies-Descriptive Statistics } \\
\hline & $\mathrm{N}$ & Minimum & Maximum & Mean & Std. Deviation & Variance \\
\hline Environment degree & 7 & 3 & 5 & 4.00 & 0.816 & 0.667 \\
\hline Equality degree & 7 & 1 & 3 & 1.43 & 0.787 & 0.619 \\
\hline Diversity degree & 7 & 1 & 3 & 1.71 & 0.756 & 0.571 \\
\hline Health and safety degree & 7 & 1 & 5 & 3.57 & 1.397 & 1.952 \\
\hline Social sustainability integration & 7 & 1 & 3 & 2.23 & 0.706 & 0.499 \\
\hline
\end{tabular}


The descriptive analysis shows higher mean values for the environmental degree for both company groups. The degree is higher in the engineering group (4.00). Standard deviation (0.816) and variance (0.667) show that the spread of data relative to mean is rather low within the group. This indicates that the group is homogeneous in terms of how they perceive the high importance of environmental sustainability. The environmental degree is medium within the high-tech group (2.77), with higher standard deviation (1.361) and variance (1.853). This indicates that the high-tech group is relatively heterogeneous in terms of how they as a group perceive the importance of environmental sustainability.

Compared to environmental sustainability, the equality and diversity degrees for the two groups are much lower. The engineering group has an equality degree of 1.43 and diversity degree of 1.71. The standard deviations for equality $(0.787)$ and diversity $(0.619)$ indicate that the group is homogeneous in terms of how they perceive the low importance of these components of social sustainability. The high-tech group has relatively higher values both for equality degree (1.69) and diversity degree (1.85) compared to the engineering group. The spread within the group shows a higher standard deviation for diversity (1.463) than equality (0.855) and the same for variance (2.141 for diversity and 0.713 for equality). Interviews also showed that the engineering group has a lower equality degree than high-tech companies, which agrees with the results of the descriptive analysis. The high standard deviation and variance for diversity shows that the high-tech companies as a group are very heterogeneous in how they perceive the importance of this component of social sustainability.

Data based on health and safety show that this component of social sustainability is considered more important compared to equality and diversity. The engineering group has a mean value of 3.57 and high standard deviation (1.397) and variance (1.952). These values show that health and safety are perceived to have medium/high importance within the group, but the spread of data is relatively high, which indicates that the group is heterogeneous. The high-tech group has a lower health and safety degree (2.00) and high standard deviation (1.225) and variance (1.500), which indicates that the spread of data relative to mean is high within the group, making the group heterogeneous.

Finally, social sustainability integration (equality, diversity, and health/safety) for the two groups shows that the mean value is lower for the social components (1.98) compared to environmental sustainability (3.20), and with standard deviation (0.763) and variance (0.583) being relatively low. All managers mentioned in interviews that they have focused on environmental sustainability more than other dimensions. The low spread indicates that social sustainability integration is perceived to have a low value within the two groups. The highest social sustainability integration is found in the engineering group (2.23), which primarily is connected to the higher value placed on health and safety. Table 3 summarizes this discussion.

Table 3. Environmental and social components—mean values and spread.

\begin{tabular}{ccccccccc}
\hline \multirow{2}{*}{ Groups } & \multicolumn{2}{c}{ Environmental } & \multicolumn{2}{c}{ Equality } & \multicolumn{2}{c}{ Diversity } & \multicolumn{2}{c}{ Health and Safety } \\
\cline { 2 - 9 } & Mean & Spread & Mean & Spread & Mean & Spread & Mean & Spread \\
\hline \multirow{2}{*}{ High-tech } & Medium & Hetero- & Low & Homo- & Low & Hetero- & Low & Hetero- \\
& $(2.77)$ & geneous & $(1.69)$ & geneous & $(1.85)$ & geneous & $(2.00)$ & geneous \\
\multirow{2}{*}{ Engineering } & High & Homo- & Low & Homo- & Low & Homo- & Medium/ & Hetero- \\
& $(4.00)$ & geneous & $(1.43)$ & geneous & $(1.71)$ & geneous & High (3.57) & geneous \\
\hline
\end{tabular}

According to Table 3, the high-tech group of companies is more heterogeneous in how they perceive environmental and social issues (except equality), while the industrial engineering companies are more homogeneous concerning environmental and social issues (except health and safety). Table 4 shows that environmental sustainability is more highly valued than social sustainability in both groups. 
Table 4. Environmental and social sustainability as integrated concepts.

\begin{tabular}{ccccc}
\hline \multirow{2}{*}{ Groups } & \multicolumn{2}{c}{ Environmental Sustainability } & \multicolumn{2}{c}{ Social Sustainability } \\
\cline { 2 - 5 } & Mean & Spread & Mean & Spread \\
\hline \multirow{2}{*}{ High-tech } & Medium & Heterogeneous & Low & \multirow{2}{*}{ Homogeneous } \\
& $(2.77)$ & & Low & Homogeneous \\
\multirow{2}{*}{ Engineering } & High & Homogeneous & $(2.23)$ & \\
& $(4.00)$ & & & \\
\hline
\end{tabular}

\subsection{The Implementation of Standards and Policies}

Table 5 shows mean values, standard deviation, and variance in the implementation of standards and policies in the two groups of companies.

Table 5. Standards and policy implementation.

\begin{tabular}{cccccc}
\hline \multicolumn{5}{c}{ High-Tech and Industrial Engineering Companies-Frequencies } \\
\hline & ISO 9001 & ISO 14001 & OHSAS 18001 & Equality Policy & Diversity Policy \\
\hline $\mathrm{N} \quad$ Valid & 20 & 20 & 20 & 20 & 20 \\
Mean & 0.650 & 0.550 & 0.350 & 0.150 & 0.200 \\
Std. Deviation & 0.489 & 0.510 & 0.489 & 0.366 & 0.410 \\
Variance & 0.239 & 0.261 & 0.239 & 0.134 & 0.168 \\
\hline \multicolumn{7}{c}{ High-Tech Companies } \\
\hline Mean & 0.540 & 0.460 & 0.230 & 0.080 \\
Std. Deviation & 0.519 & 0.519 & 0.439 & 0.277 & 0.277 \\
Variance & 0.269 & 0.269 & 0.192 & 0.077 & 0.077 \\
\hline \multicolumn{7}{c}{ Industrial Engineering Companies } \\
\hline Mean & 0.860 & 0.710 & 0.570 & 0.290 & 0.430 \\
Variance & 0.378 & 0.488 & 0.535 & 0.488 & 0.535 \\
\end{tabular}

The analysis shows that the IS09001 has the highest mean $(0.65$, the scale $0-1$ yields $65 \%)$. The low spread within the two groups indicates that many of the companies have implemented quality management systems, ISO 9001, followed by ISO 14001 (55\%). The socially oriented guidelines (OHSAS 18001, equality and diversity policies) have low values, indicating that these are perceived to be of less importance to implement. Notice that the high-tech companies group has lower mean values in all standards compared to the engineering group. Relatively low standard deviation and variance in all standards and policies indicate that both groups are homogeneous in standard implementation importance.

Table 6 shows that the mean value for the implementation of standards and policies is higher in the engineering group. In the high-tech group, $76.9 \%$ have no to low degree of standard implementation, compared to $28.6 \%$ for the engineering group.

Table 6. Degree of standard implementation in high-tech and industrial engineering companies.

\begin{tabular}{cc}
\hline \multicolumn{3}{c}{ High-Tech Companies } \\
\hline Mean & 1.460 \\
Std. Deviation & 1.561 \\
Variance & 2.436 \\
\hline & Industrial Engineering Companies \\
\hline Mean & 2.860 \\
Std. Deviation & 1.864 \\
Variance & 3.476 \\
\hline
\end{tabular}


Table 6. Cont.

\begin{tabular}{|c|c|c|c|c|c|}
\hline \multicolumn{6}{|c|}{ High-Tech Companies } \\
\hline \multicolumn{2}{|c|}{ Degree of standard implementation } & Frequency & Percent & Valid Percent & $\begin{array}{c}\text { Cumulative } \\
\text { Percent }\end{array}$ \\
\hline \multirow{6}{*}{ Valid } & None & 5 & 38.5 & 38.5 & 38.5 \\
\hline & Very low & 2 & 15.4 & 15.4 & 53.8 \\
\hline & Low & 3 & 23.1 & 23.1 & 76.9 \\
\hline & Some & 2 & 15.4 & 15.4 & 92.3 \\
\hline & Very high & 1 & 7.7 & 7.7 & 100.0 \\
\hline & Total & 13 & 100.0 & 100.0 & \\
\hline \multicolumn{6}{|c|}{ Industrial Engineering Companies } \\
\hline & & Frequency & Percent & Valid Percent & $\begin{array}{c}\text { Cumulative } \\
\text { Percent }\end{array}$ \\
\hline \multirow{5}{*}{ Valid } & None & 1 & 14.3 & 14.3 & 14.3 \\
\hline & Very low & 1 & 14.3 & 14.3 & 28.6 \\
\hline & Some & 3 & 42.9 & 42.9 & 71.4 \\
\hline & Very high & 2 & 28.6 & 28.6 & 100.0 \\
\hline & Total & 7 & 100.0 & 100.0 & \\
\hline
\end{tabular}

Finally, we calculated how the sustainability degree correlates to the companies' implementation of standards and policies, which returned the value 0.388 . This indicates that the companies overestimate their use of sustainability components in relationship to standard and policy implementation or underestimate when communicating their usage of these instruments.

\subsection{Social Sustainability as Practiced}

\subsubsection{In High-tech Companies}

All the high-tech managers believe it is important to work with social issues and that it is of great importance to improve this work. Respondents see sustainability as a success concept for staying the market- "to win or disappear" (ID 2), as a way "to get good will with high impact on performance" (ID 6), as the "green gold" to create new value chains, new products, and new ways to do business integrated in company activities, improving the working culture (ID 13), and as a way "to be attractive as an employer" (ID 3).

The interviewees argued that they lack formal tools to improve equality between the sexes and to work with diversity. Even if policies exist, these are mainly seen as "silent" documents. Most social-related work is, according to the respondents, handled by payroll administrators who aim to reduce wage differentials, because the men's salaries are higher. The HR managers argue that they take into account gender equality in recruitment, in management, and in the Board.

To apply the sustainability concept more efficiently, the high-tech companies ask for the following:

- more collaboration among companies for skill development (ID 2);

- clearer internal strategies to achieve gender equality and diversity (IDs 6 and 12);

- more women to look for technical work typically done by males, which requires education (ID 4);

- a better way to handle cultural resistance to change (IDs 1 and 7);

- clearer tools and an agenda to follow to obtain a more tolerant and inclusive working environment (ID 3).

\subsubsection{In Industrial Engineering Companies}

Above all, the industrial engineering companies pay attention to safety issues regarding the working environment. According to company 14, ISO 9001 covers social issues, and employee satisfaction is measured once a year. Most companies train employees in security, but mostly at the 
management level. The companies have a safety committee managing health and safety issues with (1) meetings and safety training (ID 15), (2) procedures to take corrective action for safety in the workplace (ID 16), or (3) research that includes questions about sexual harassment, health/illness, and well-being (ID 16). The employee satisfaction survey is conducted with the help of consultants (IDs 15 and 19). Company 19 reported that it is difficult to attract women to work in industrial engineering companies. One obstacle commonly mentioned is how to define sustainable development.

\section{Discussion}

Previous researchers have emphasized several strategic reasons why companies should implement social sustainability $[2,27,35,36]$. In particular, companies need to have a positive image to be attractive to key stakeholders [6,37]. The findings show that the industrial engineering companies and the high-tech companies define, prioritize, and formally implement sustainability in different ways. While the high-tech companies are heterogeneous and define social sustainability as of low importance, the industrial engineering companies are homogeneous but define environmental and safety issues as most important.

Both groups showed a low interest in implementing social sustainability issues relating to equality and diversity. There are considerable differences within the high-tech group in how the companies work with social sustainability and how the managers want them to work. The companies in the engineering group do not prioritize social concerns and express no desire to develop social sustainability further. These companies mostly discuss supply chain compliance and, above all, how to reduce costs while following their corporate code of conduct. Mirvis et al. discuss three reasons, confirmed by this study, for this gap between company operations and management wishes [6]. First, the studied companies did not have a clear or united view on sustainability, as is indicated by the high heterogeneous degree among high-tech companies. These companies also mention that concepts like CSR and social sustainability are difficult to define. They emphasize the need for training and the use of tools that ease the work for them. Ma and Okudan Kremer [47] also believe that the only way to evaluate problems related to sustainability is to balance the impact of the environmental, economic, and social dimensions, especially as the human aspects also have impact on economic decisions and improvement. These findings are in line with Boström's discussion of how barriers to knowing what sustainability is make it difficult to operationalize [33].

Company vision, mission, and values can act as "guideposts to sustainability" to identify and set the frames of action [6]. How companies strategically and innovatively act based on company policies following core values plays a significant role in how they achieve the main goals having an impact on social sustainability strategy. Most companies in this study have implemented ISO 9001 and ISO 14001, but many of them lack standards and policies helpful in supporting the implementation of social sustainability, especially in the case of equality and diversity. The high-tech companies' HR managers strongly believe that they will need to further develop plans and policies, but the CEOs believe that bringing innovations to the market is what the company needs to focus on. This may explain why high-tech companies are heterogeneous: many of the CEOs attach more importance to getting innovations to market than devoting time to social conditions. Secondary data from the high-tech companies' websites show that they pay greater attention to the image of their product innovations than to sustainability factors.

The second reason for the gap between company operations and management wishes mentioned by Mirvis et al. is that there is no coordination of who is responsible for environmental, social, and governance issues, nor any agreement on how to handle them [6]. In the studied companies, sustainability work is often divided depending on organizational function and relevance to work. While HR managers in the high-tech group have a good understanding of the human aspects, they profess less knowledge of how to manage social and other sustainability issues in operational activities. Managers in the engineering group, who work with production-related issues and codes of conduct, are keener to focus attention on health and safety and diversity issues than those belonging to production-related 
responsibility bias. How the organization defines sustainability depends on how important issues are to work function, also making it difficult to prioritize the issues. This means that how sustainability is defined is linked to business function rather than integrated as a part of business strategy.

The third reason for the gap mentioned by Mirvis et al. is that many companies don't make a strong commitment to sustainability [6]. The data indicates major problems with equality and diversity, which means that deficiencies still exist (e.g., most of their employees are men). It indicates that the companies' employment culture is institutionalized, with routines that are difficult to change. Understanding the preconditions of social norms and values as part of the culture is most significant [27]. Factors relating to social sustainability are not integrated into the organization as culture, which indicates a low commitment to addressing equality issues.

\section{Conclusions}

This study analyzed how social sustainability is defined and implemented in high-tech and industrial engineering companies' core activities. To improve comparability, environmental factors were also included in the calculations. Evidently, high-tech companies attach lower importance to integrating social sustainability as part of their business operations. Instead, they prioritize accelerating innovations to the market. The findings show that the high-tech companies pay limited attention to integrating environmental factors into business operations. As a group, they are heterogeneous, indicating there are differences in how the companies value the integration of social sustainability in business operations.

The industrial engineering companies are more interested in implementing environmental sustainability into business operations. Regarding social sustainability, they are heterogeneous in how they prioritize factors related to health and safety and homogeneous in how they devote low attention to equality and diversity. Health and safety issues are part of the corporate code of conduct and are valued and given greater importance. Social issues related to equality and diversity are not reflected upon at all. While measurements of the work environment are carried out, this is merely part of an annual routine rather than a strategic part of business operations.

Generally, the findings of the study show that social sustainability as an integrated concept is undervalued in both company groups. A low value between how the respondents perceive that they operationalize sustainability compared with how they implement it in practice with the support of standards and policies shows that they underestimate the need for support or overestimate the efforts that are made. Hence, the companies show low readiness to meet the social, legal, and competitive demands required by an innovative work environment. The findings also show differences between the companies, which can mean that the activities in different companies require different dimensions of sustainability. The requirements of the engineering companies make them prioritize environmental issues due to receiving complaints.

This study provides both theoretical and practical contributions. Theoretically, the study contributes by developing a model for how to calculate and compare companies' evaluations of environmental and social components. Furthermore, the data shows that the social dimension of sustainability is ranked low. Companies that do engage in sustainability link their efforts to social components based on economic and cost-related decisions. Practically, the study contributes to managerial knowledge in showing the need to educate people and integrate social sustainability into business operations, if the goal is to attract skilled employees and compete in the face of new legal requirements. Because the companies in the study were selected and based on a small sample set, the results provide an illustration of the challenges that exist in the companies related to the implementation of social sustainability. Hence, further research is needed to confirm the findings of this study.

The study had several limitations. First, the choice of companies was limited both in number and context. The two groups of companies represent different lines of business, but the point was to illustrate how social sustainability is managed in separate, not easily comparable industrial settings. 
Limiting the study to high-tech and engineering industries with traditions of a male-dominated workforce could be criticized for making it difficult to generalize and compile the findings. Still, we argue that the companies can be seen as representative of other businesses in the same position (male-dominated employment) and located in the same two types of industrial contexts.

Given these limitations, we suggest additional studies on how companies in other business contexts and industries manage social sustainability. More studies are needed to investigate the effects of social sustainability integration after the new legal requirements come into force.

Author Contributions: Writing—original draft, A.S.; Writing—review and editing, Z.A. and K.M.

Funding: This research received no external funding.

Conflicts of Interest: The authors declare no conflict of interest.

\section{References}

1. Sundström, A.; Hyder, A.S. Local management response to corporative restructuring: A case study of a company town. Bus. Soc. Rev. 2008, 113, 375-402. [CrossRef]

2. Katsoulakos, T.; Katsoulakos, Y. Integrating corporate responsibility principles and stakeholder approaches into mainstream strategy: Stakeholder-oriented and integrative strategic management framework. Corp. Gov. 2007, 7, 355-369. [CrossRef]

3. Spangenberg, J.H. The Corporate Human Development Index CHDI: A tool for corporate social sustainability management and reporting. J. Clean. Prod. 2016, 134, 414-424. [CrossRef]

4. Ma, J.; Kremer, G.E. A fuzzy logic-based approach to determine product component EOL option from the combination of sustainability and designer's perception. J. Clean. Prod. 2015, 108, 289-300. [CrossRef]

5. Ma, J.; Harstvedt, J.D.; Dunaway, D.; Bian, L.; Jaradat, R. An exploratory investigation of additively manufactured product life cycle sustainability assessment. J. Clean. Prod. 2018, 192, 55-70. [CrossRef]

6. Mirvis, P.; Googins, B.; Kinnicutt, S. Vision, mission and values: Guideposts to sustainability. Organ. Dyn. 2010, 39, 316-324. [CrossRef]

7. Huq, F.A.; Stevenson, M.; Zorzini, M. Social sustainability in developing country suppliers: An exploratory research in the readymade garments industry of Bangladesh. Int. J. Oper. Prod. Manag. 2014, 34, 610-638.

8. Husser, J.; André, J.-M.; Barbat, G.; Lespinet-Najib, V. CSR and sustainable development: Are the concepts compatible? Manag. Environ. Qual. Int. J. 2011, 23, 658-672. [CrossRef]

9. Colgan, F. Equality, diversity and corporate responsibility: Sexual orientation and diversity management in the UK private sector. Equal. Divers. Incl. Int. J. 2011, 30, 719-734. [CrossRef]

10. Ravazzani, S. Understanding approaches to managing diversity in the workplace. An empirical investigation in Italy. Equal. Divers. Incl. Int. J. 2016, 35, 154-168. [CrossRef]

11. Calabrese, A.; Costa, R.; Rosati, F. Gender differences in customer expectations and perceptions of corporate social responsibility. J. Clean. Prod. 2016, 116, 135-149. [CrossRef]

12. Granerud, L. Social responsibility as an intermediary for health and safety in small firms. Int. J. Workplace Health Manag. 2011, 4, 109-122. [CrossRef]

13. Rawlingson, F; Farrell, P. UK construction industry site health and safety management. An examination of promotional web material as an indicator of current direction. Constr. Innov. 2010, 10, 435-446. [CrossRef]

14. Statistics Sweden. Available online: http://www.scb.se (accessed on 10 April 2019).

15. Project Everyone. The 17 goals. Available online: https://www.globalgoals.org/ (accessed on 11 June 2019).

16. European Commission. 2016. Available online: http://ec.europa.eu/small-business/most-of-market/humanresources/index_en.htm\#5 (accessed on 2 May 2016).

17. Kira, M.; van Eijnatten, F.M. Socially sustainable work organizations and systems thinking. Syst. Res. Behav. Sci. 2010, 27, 713-721. [CrossRef]

18. Sundström, A. Globalization, CSR and Business Legitimacy in Local Relationships. Ph.D. Dissertation, Swedish University of Agricultural Sciences, Uppsala, Sweden, 2009.

19. Siegel, D.S.; Vitaliano, D.F. An empirical analysis of the strategic use of corporate social responsibility. J. Econ. Manag. Strategy 2007, 16, 773-792. [CrossRef]

20. Quinn, D.P.; Jones, T.M. An agent morality view of business policy. Acad. Manag. Rev. 1995, 20, $22-42$. [CrossRef] 
21. Porter, M.E.; Kramer, M.R. Strategy and society: The link between competitive advantage and corporate social responsibility. Harv. Bus. Rev. 2006, 84, 78-92.

22. Liao, S.-H.; Chang, W.-J.; Wu, C.-C.; Katrichis, J.M. A survey of market orientation research (1995-2008). Ind. Mark. Manag. 2011, 40, 301-310. [CrossRef]

23. Hurley, R.F.; Hult, G.T.M. Innovation, market orientation and organizational learning: An integration and empirical examination. J. Mark. 1998, 63, 42-54. [CrossRef]

24. Menguc, B.; Auh, S. Creating a firm-level dynamic capability through capitalizing on market orientation and innovativeness. J. Acad. Mark. Sci. 2006, 34, 63-73. [CrossRef]

25. Krica, A.H.; Jayachandran, S.; Bearden, W.O. Market orientation: A meta-analytic review and assessment of its antecedents and impact on performance. J. Mark. 2005, 69, 24-41. [CrossRef]

26. Noble, C.H.; Sinha, R.K.; Kumar, A. Market orientation and alternative strategic orientations: A longitudinal assessment of performance implications. J. Mark. 2002, 66, 25-39. [CrossRef]

27. Vallance, S.; Perkins, H.C.; Dixon, J.E. What is social sustainability? A clarification of concepts. Geoforum 2011, 42, 342-348. [CrossRef]

28. Lin, Y.; Zhang, X.; Greetman, S. Towards smart governance and social sustainability for Chinese migrant communities. J. Clean. Prod. 2015, 107, 389-399. [CrossRef]

29. Mani, V.; Agrwal, R.; Sharma, V. Supplier selection using social sustainability: AHP based approach in India. Int. Strateg. Manag. Rev. 2014, 2, 98-112. [CrossRef]

30. Källström, H.N.; Ljung, M. Social sustainability and collaborative learning. Ambio 2005, 34, 378-382. [CrossRef]

31. Nahapiet, J.; Ghosal, S. Social capital, intellectual capital and the organizational advantage. Acad. Manag. 1998, 23, 242-266.

32. Redclift, M. Sustainable development (1987-2005): An oxymoron comes of age. Sustain. Dev. 2005, 13, 212-227. [CrossRef]

33. Boström, M. A missing pillar? Challenges in theorizing and practicing social sustainability: Introduction to the special issue. Sustain. Sci. Pract. Policy 2012, 8, 3-14. [CrossRef]

34. Longoni, A.; Golini, R.; Cagliano, R. The role of new forms of work organization in developing sustainability strategies in operations. Int. J. Prod. Econ. 2014, 147, 147-160. [CrossRef]

35. Blake-Beard, S.; O'Neill, R.; Ingols, C.; Shapiro, M. Social sustainability, flexible work arrangements, and diverse women. Gend. Manag. Int. J. 2010, 25, 408-425. [CrossRef]

36. Galuppo, L.; Gorli, M.; Scaratti, G.; Kaneklin, C. Building social sustainability: Multi-stakeholder processes and conflict management. Soc. Responsib. J. 2014, 10, 685-701. [CrossRef]

37. Kira, M.; van Eijnatten, F.M. Socially sustainable work organizations: A chaordic system approach. Syst. Res. Behav. Sci. 2008, 25, 743-756. [CrossRef]

38. Dempsey, N.; Bramley, G.; Power, S. The social dimension of sustainable development: Defining urban. Soc. Sustain. 2011, 19, 289-300.

39. United Nations Global Compact. The Ten Principles. 2012. Available online: https://www.unglobalcompact. org/abouttheGC/thetenprinciples/index.html (accessed on 8 June 2015).

40. Brewer, J.; Hunter, A. Foundations of Multimethod Research, Synthesizing Styles; Sage Publications: Thousand Oaks, CA, USA, 2005.

41. Gil-Garcia, J.R.; Pardo, T.A. Multi-method approaches to understanding the complexity of e-government. Int. J. Comput. Syst. Signals 2006, 7, 3-17.

42. Creswell, J.W.; Plano Clark, V.L.; Gutmann, M.L.; Hanson, W.E. Advanced mixed methods research designs. In Handbook of Mixed Methods in Social and Behavioral Research; Tashakkori, A., Teddlie, C., Eds.; Sage: Thousand Oaks, CA, USA, 2003; pp. 209-240.

43. Esteves, J.; Pastor, J. Using a multimethod approach to research enterprise systems implementations. Electron. J. Bus. Res. Methods 2004, 2, 69-82.

44. Johnson, R.B.; Onwuegbuzie, A.J. Mixed methods research: A research paradigm whose time has come. Educ. Res. 2004, 33, 14-26. [CrossRef]

45. Ghauri, P.; Grönhaug, K. Research Methods in Business Studies-A Practical Guide, 4th ed.; Pearson Education: New York, NY, USA, 2010. 
46. Powers, A.D.; Xie, Y. Statistical Methods for Categorical Data Analysis, 1st ed.; Academic Press: Cambridge, MA, USA, 2000.

47. Ma, J.; Okudan Kremer, G.E. A modular product design approach to improve product social sustainability performance. In Proceedings of the 2015 ASME International Design Engineering Technology Conference and Computers and Information in Engineering Conference, Boston, MA, USA, 2-5 August 2015.

(c)

(C) 2019 by the authors. Licensee MDPI, Basel, Switzerland. This article is an open access article distributed under the terms and conditions of the Creative Commons Attribution (CC BY) license (http://creativecommons.org/licenses/by/4.0/). 